\title{
A copper(II)-macrocycle complex for sensing biologically-relevant organic anions in a competitive fluorescence assay: oxalate sensor or urate sensor?
}

David Hontz ${ }^{a}$, Jayden Hensley ${ }^{b}$, Kayla Hiryak ${ }^{b}$, Jennifer Lee ${ }^{b}$, Jared Luchetta ${ }^{a}$, Maria Torsiello ${ }^{b}$, Michael Venditto ${ }^{b}$, Del Lucent ${ }^{c}$, William Terzaghi ${ }^{d}$, Donald Mencer ${ }^{a}$, Ajay Bommareddy ${ }^{b}$, and Adam L. VanWert ${ }^{*} b$

a. Department of Chemistry \& Biochemistry, College of Science and Engineering, Wilkes University, 84 W South St., Wilkes-Barre, PA 18766, USA.

b. Department of Pharmaceutical Sciences, Nesbitt School of Pharmacy, Wilkes University, 84 W South St., Wilkes-Barre, PA 18766, USA. E-mail: adam.vanwert@wilkes.edu

c. Department of Electrical Engineering and Physics, College of Science and Engineering, Wilkes University, 84 W South St., Wilkes-Barre, PA 18766, USA.

d. Department of Biology, College of Science and Engineering, Wilkes University, 84 W South St., Wilkes-Barre, PA 18766, USA. 

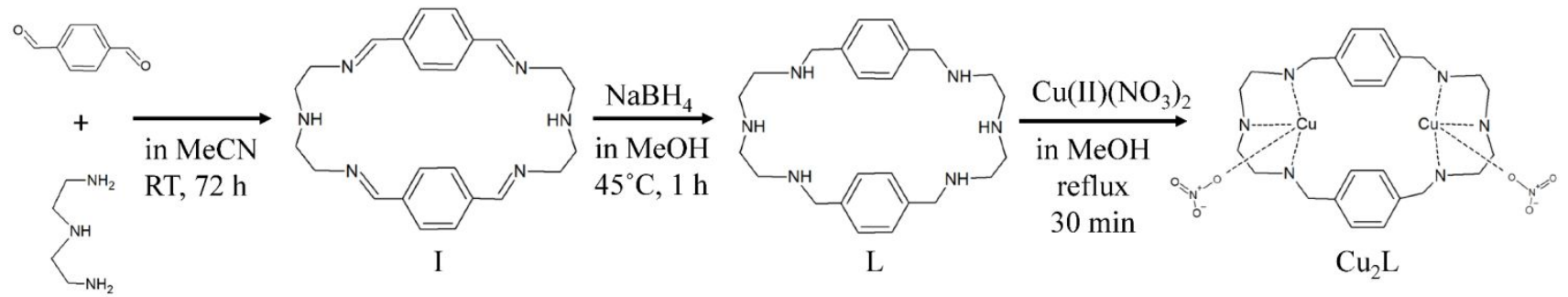

Figure S1. Synthesis of $\mathrm{Cu}_{2} \mathrm{~L}$.

a

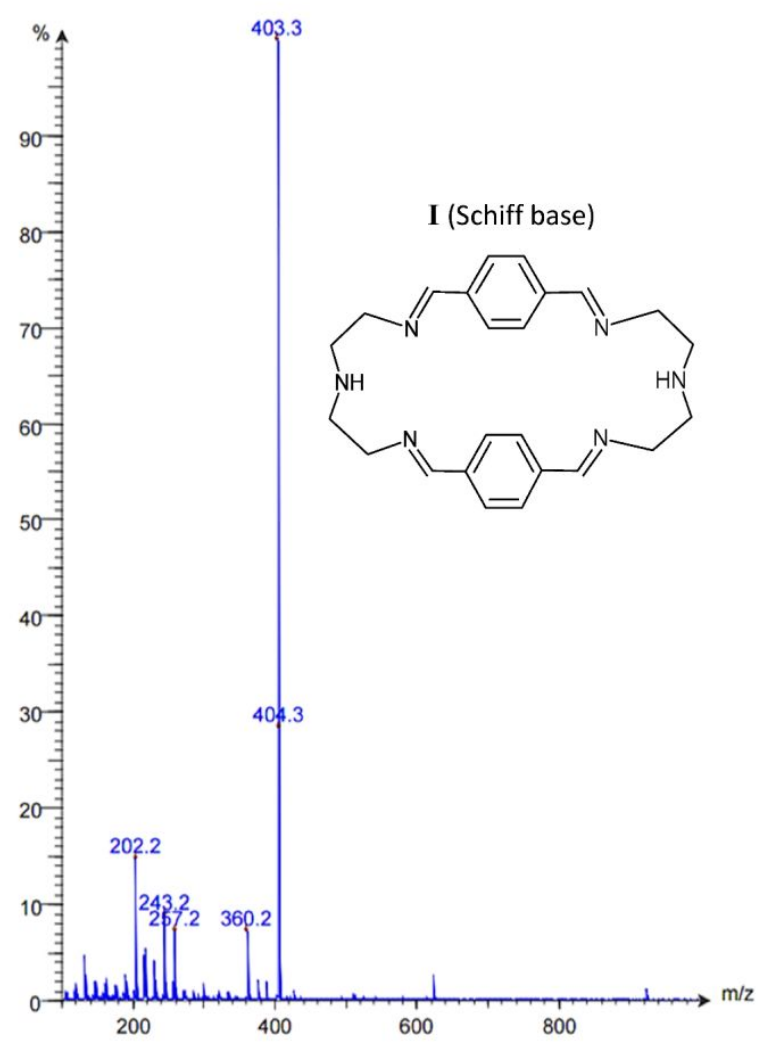

b

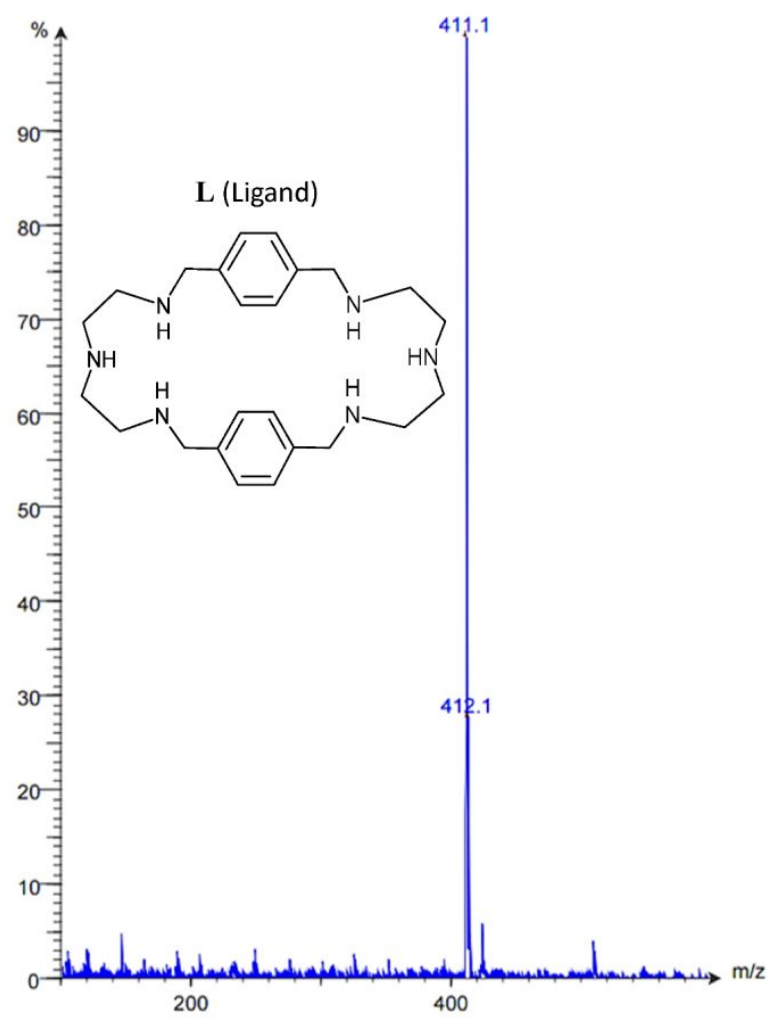

Figure S2. ESI Mass Spectra of $\mathbf{I}$ and L. (a) Expected $\mathrm{m} / \mathrm{z}$ for singly protonated $\mathbf{I}$ is 403.261 , and (b) singly protonated $\mathbf{L}$ is 411.324 . 


\section{NMR of Schiff Base (I) and Ligand (L).}

3,6,9,16,19,22-Hexazatricyclo[22.2.2.2 $2^{11,14}$ ]triaconta-1(27),2,9,11,13,15,22,24(28),25,29decaene (I): ${ }^{1} \mathrm{H}$ NMR $\left(\mathrm{CDCl}_{3}, 400 \mathrm{MHz}\right)$ : $\delta 3.039(\mathrm{~m}, 8 \mathrm{H}), 3.836(\mathrm{~m}, 8 \mathrm{H}), 7.584(\mathrm{~s}, 8 \mathrm{H})$, $8.342(\mathrm{~s}, 4 \mathrm{H}) .{ }^{13} \mathrm{C} \mathrm{NMR}\left(\mathrm{CDCl}_{3}, 100 \mathrm{MHz}\right): \delta 48.53,59.88,128.12,137.82,161.72$.

3,6,9,16,19,22-Hexazatricyclo[22.2.2.2 $\left.{ }^{11,14}\right]$ triaconta-1(27),11,13,24(28),25,29-hexaene (L): ${ }^{1} \mathrm{H} \mathrm{NMR}\left(\mathrm{CDCl}_{3}, 400 \mathrm{MHz}\right): \delta$ 2.814-2.874 (dd, 16H), 3.797 (s, 8H), 7.293 (s, 9.5H). ${ }^{13} \mathrm{C} \mathrm{NMR}\left(\mathrm{CDCl}_{3}, 100 \mathrm{MHz}\right): \delta 48.961,49.078,53.82,128.22,139.31$.

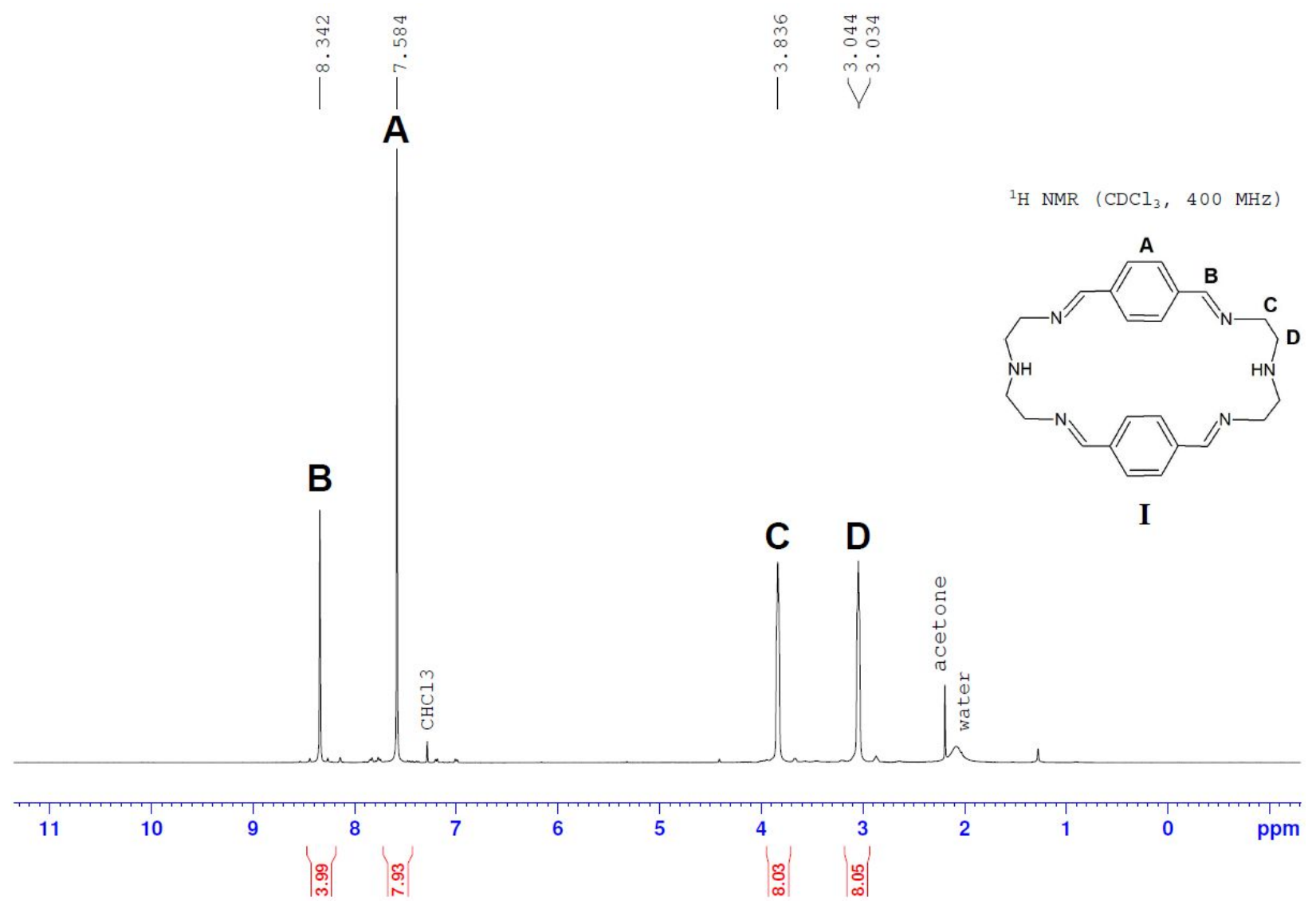

Figure S3. ${ }^{1} \mathrm{H}$ NMR spectrum of I ( $\left.\mathrm{CDCl}_{3}, 400 \mathrm{MHz}\right)$. Letters on structure correspond to labels on spectrum. 


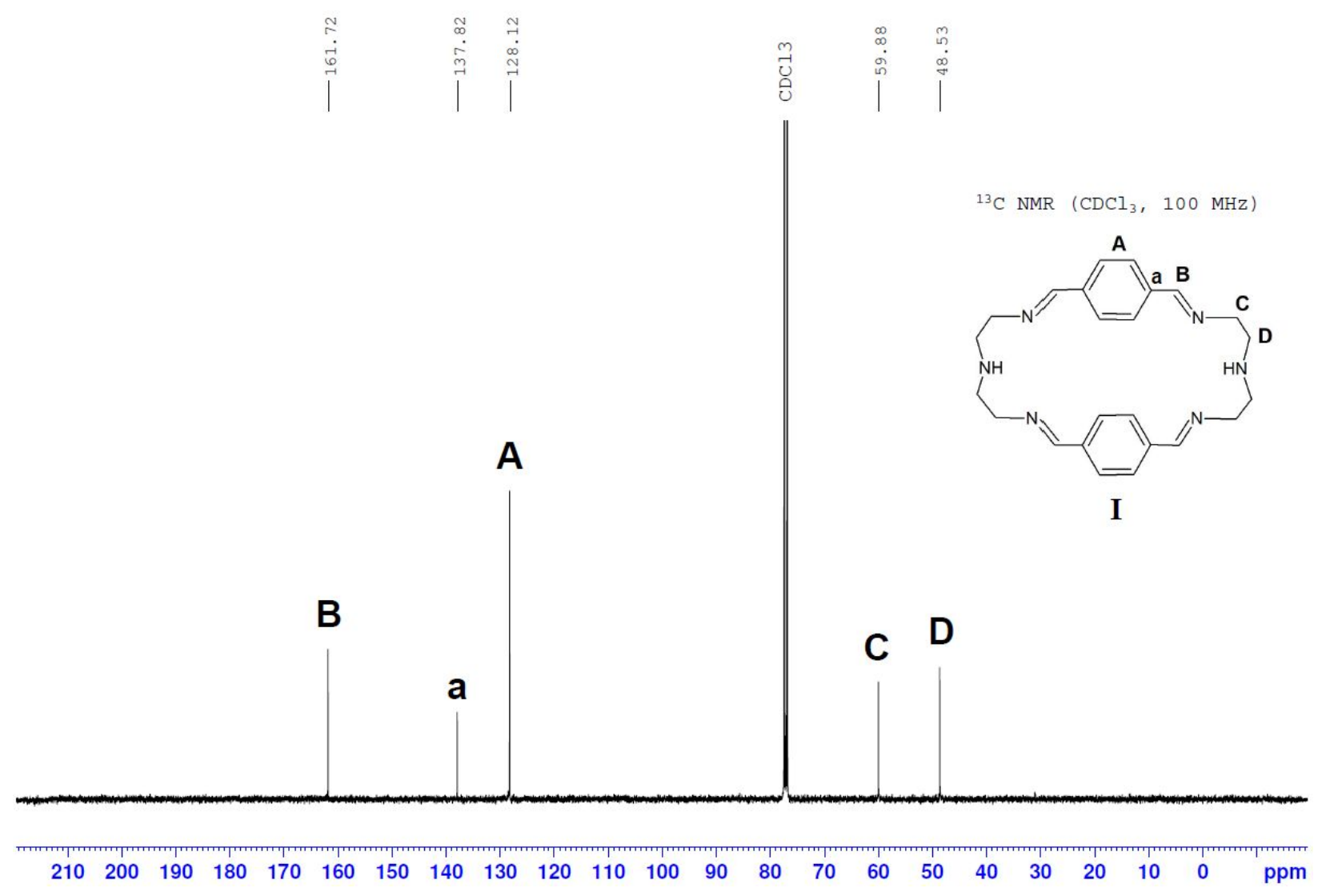

Figure S4. ${ }^{13} \mathrm{C}$ NMR spectrum of I $\left(\mathrm{CDCl}_{3}, 100 \mathrm{MHz}\right)$. Letters on structure correspond to labels on spectrum. 


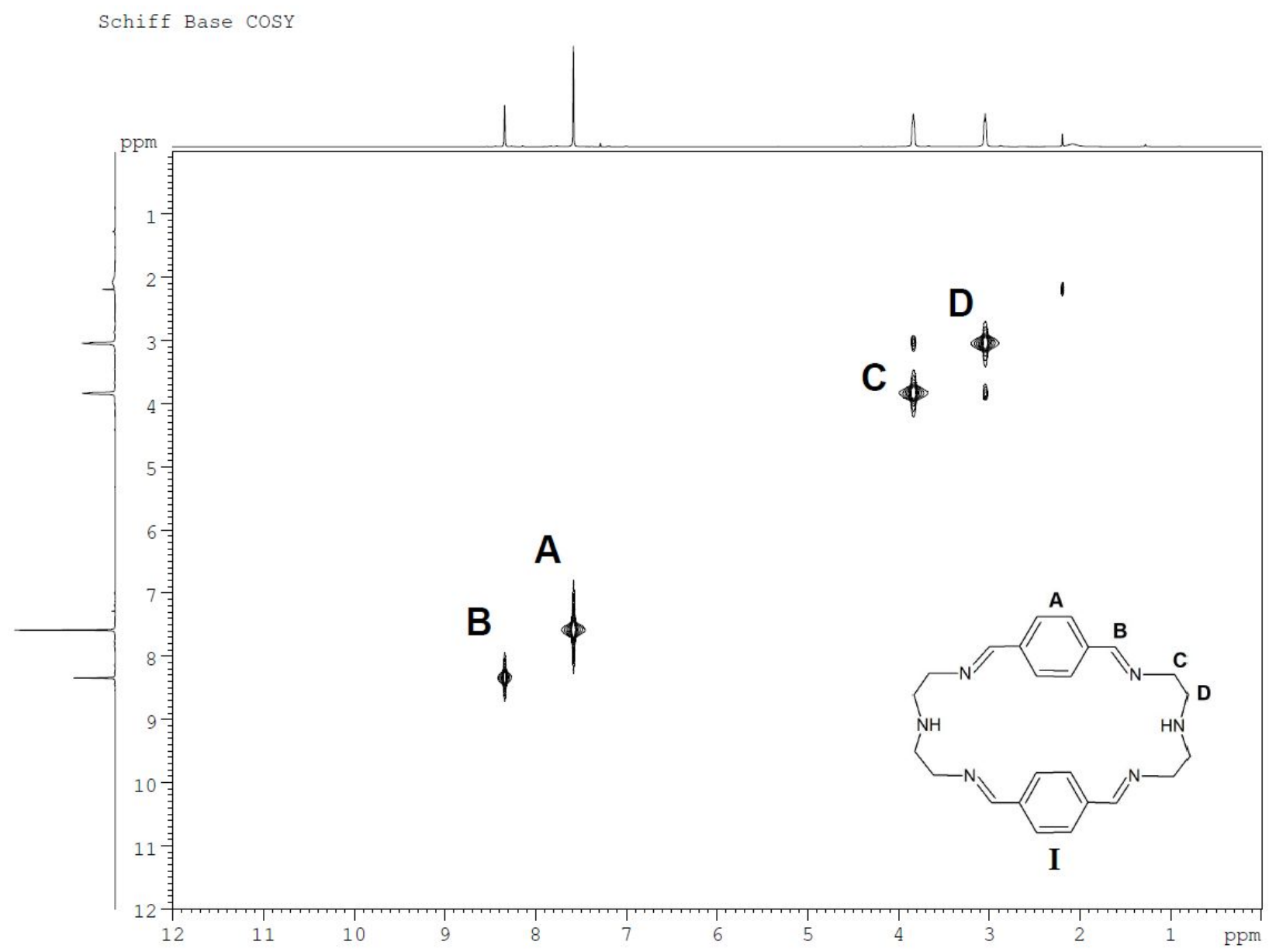

Figure S5. Homonuclear correlation spectroscopy (COSY) of I. Letters on structure correspond to labels on spectrum. 


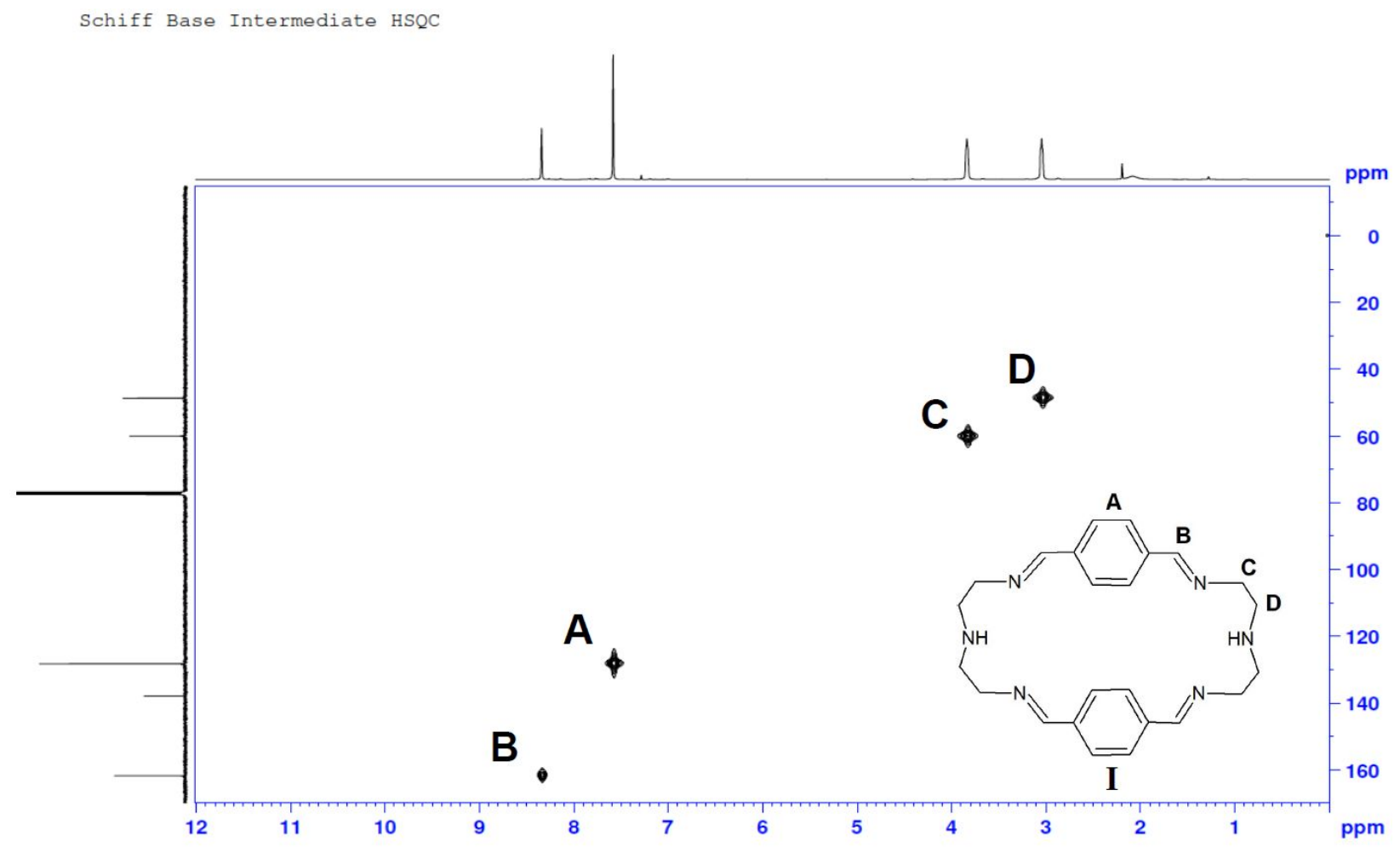

Figure S6. Heteronuclear single quantum correlation (HSQC) of I. Letters on structure correspond to labels on spectrum. 


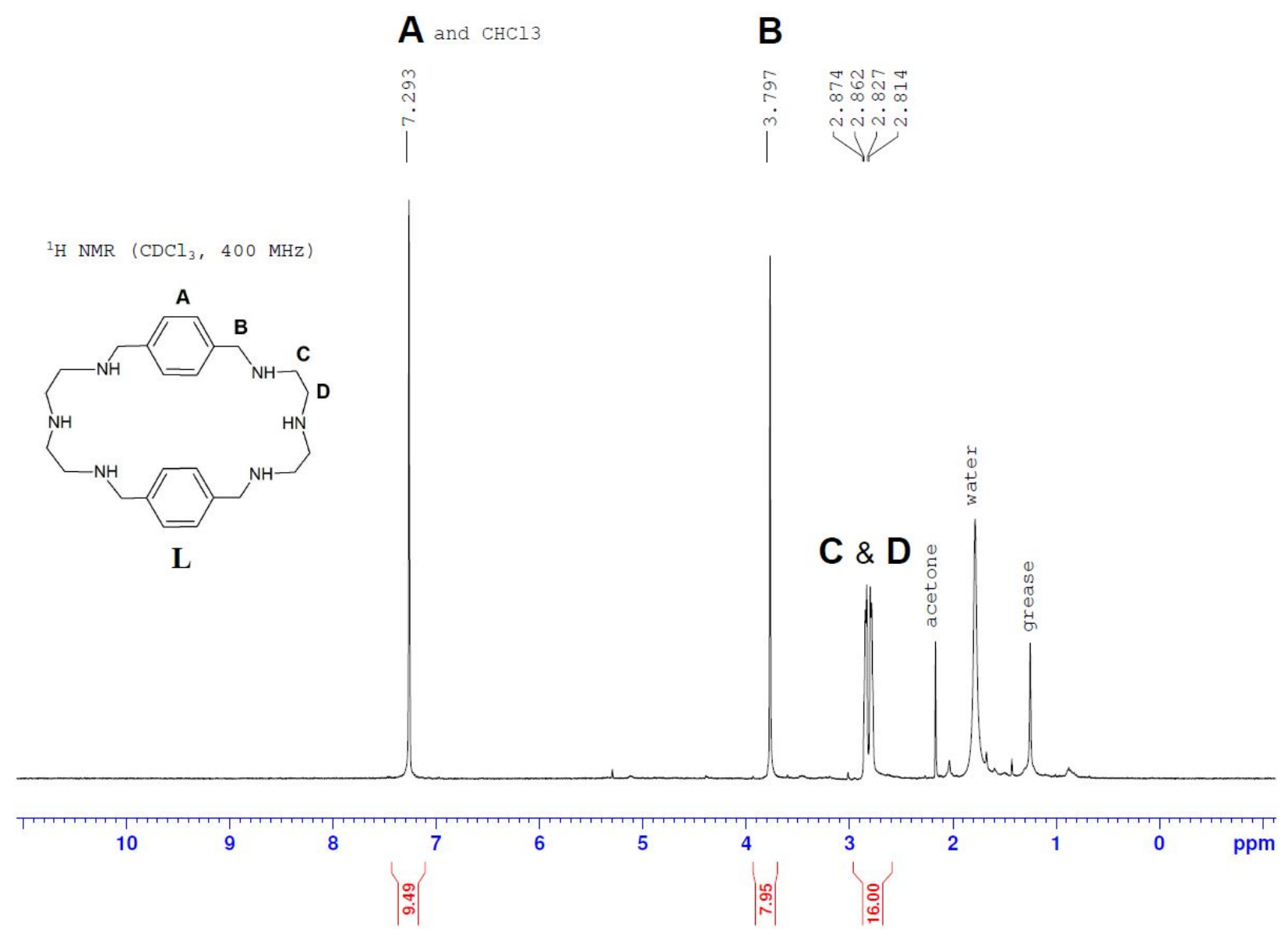

Figure S7. ${ }^{1} \mathrm{H}$ NMR spectrum of $\mathrm{L}\left(\mathrm{CDCl}_{3}, 400 \mathrm{MHz}\right)$. Letters on structure correspond to labels on spectrum. 


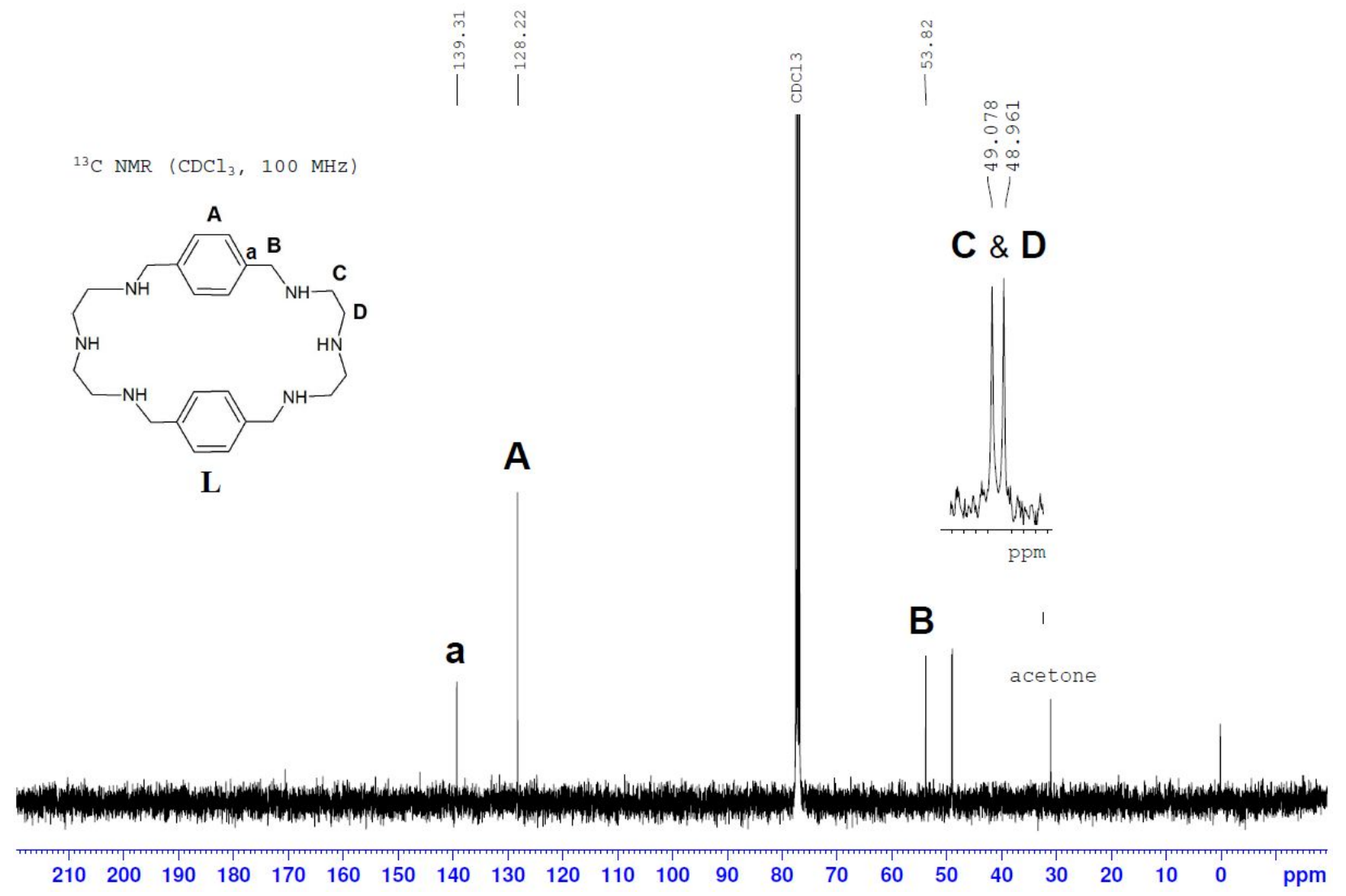

Figure S8. ${ }^{13} \mathrm{C}$ NMR spectrum of $\mathrm{L}\left(\mathrm{CDCl}_{3}, 100 \mathrm{MHz}\right)$. Letters on structure correspond to labels on spectrum. 


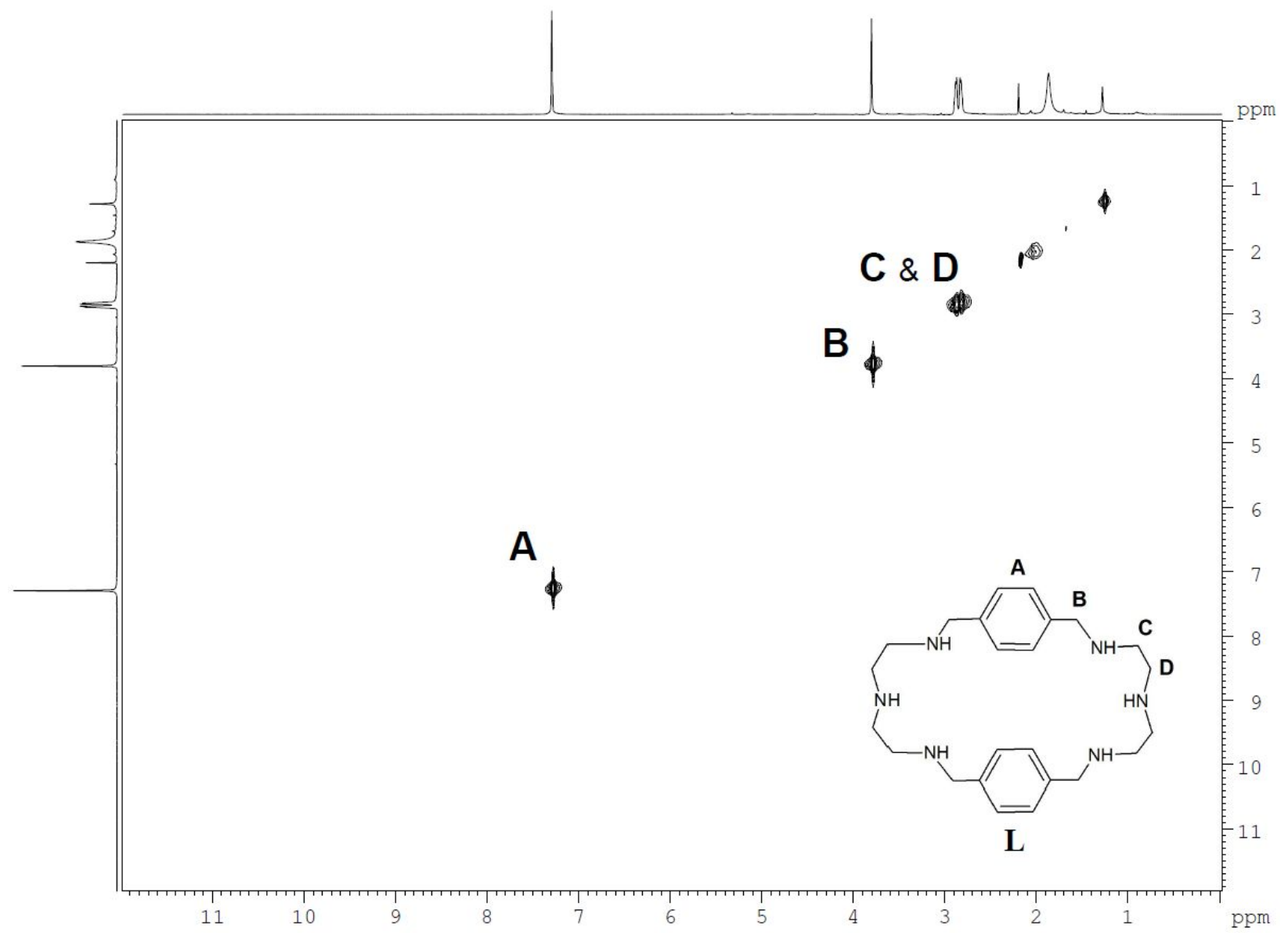

Figure S9. Homonuclear correlation spectroscopy (COSY) of L. Letters on structure correspond to labels on spectrum. 


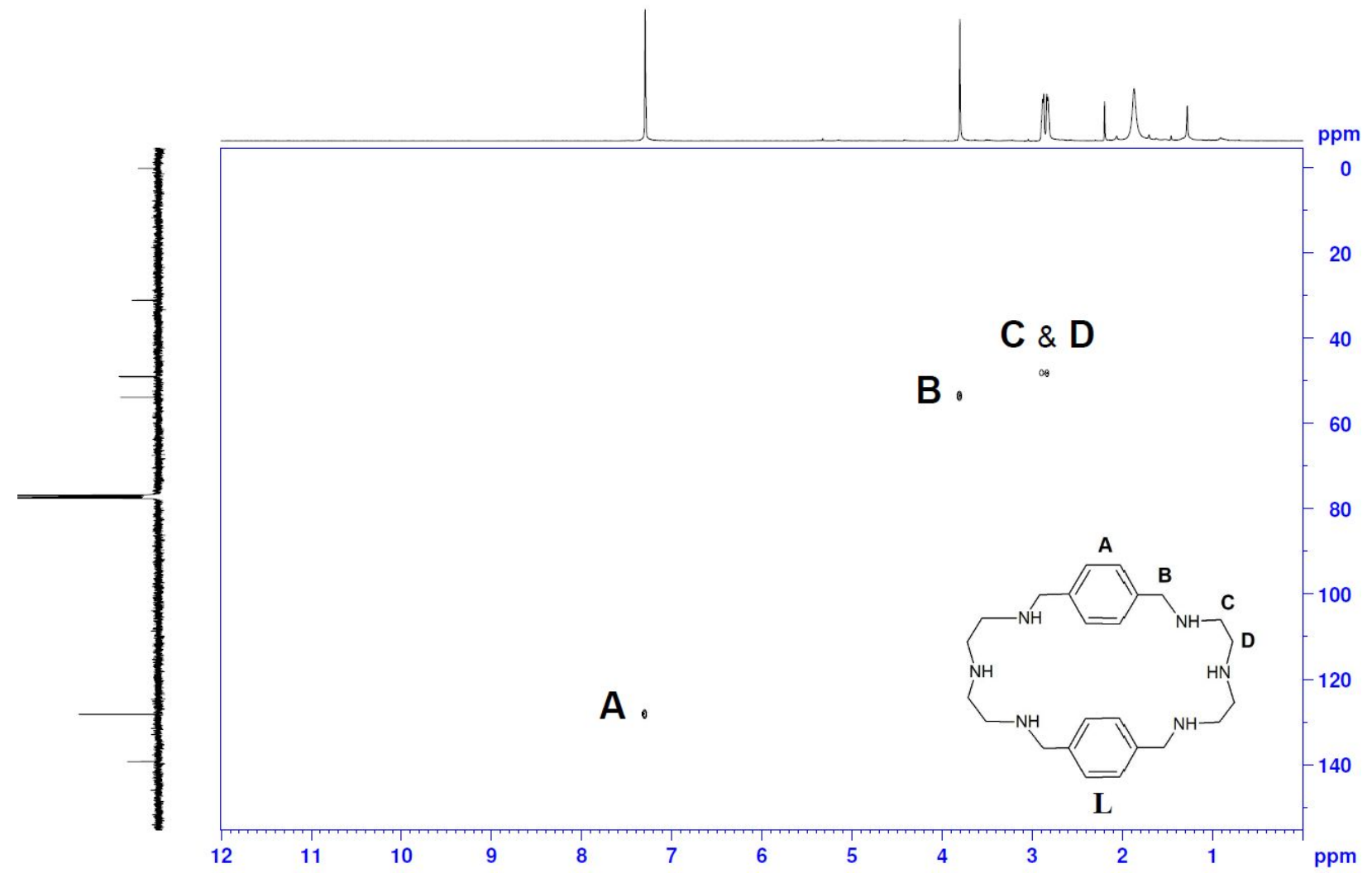

Figure S10. Heteronuclear single quantum correlation (HSQC) of L. Letters on structure correspond to labels on spectrum. 